\title{
MONITORING WORK PARAMETERS FOR ROAD TRANSPORT MEANS
}

\author{
Radu Ciuperca, Ancuta Nedelcu, Ana Zaica, Alexandra Anghelet \\ National Institute of Research-Development for Machines and Installations Designed to Agriculture \\ and Food Industry, Romania \\ ciupercaradu@yahoo.com,nedelcuus@yahoo.com,zaica_ana@yahoo.com, \\ anghelet.alexandra@yahoo.com
}

\begin{abstract}
The performance of the transport means is also determined by the rolling systems, which have major economic and environmental implications caused by the loads to be carried, the travel speeds, the constructive and functional characteristics, the air pressure in the tires with direct implications on the compaction and wear of the rolling track, tire tread wear, rolling resistance and implicitly of the cost of the transport operation itself. The subject of the present paper is the research carried out on a moving articulated vehicle made up of an agricultural tractor and semi-trailer, aiming to continuously monitor the dynamic parameters of the vehicle. We present the mathematical relations expressing the action of the semi-trailer on the tractor, represented by connecting forces, moments and loads, identifying in particular the reaction of the ground on the semi-trailer rolling system and load transfer from the semi-trailer to the tractor, which contributes to its additional loading, these two parameters being followed. For the continuous measurement and monitoring of the two parameters, in real time, a load monitoring installation was built and assembled on the articulated vehicle, consisting mainly of force transducers, force amplifiers, micro PLC operating terminal and other connection elements. Registrations made during the experiments are managed by software specially created for these researches. Experiments were carried out both for stationary and for all travel regimes of the articulated vehicle, namely acceleration, deceleration and sudden braking, the results obtained from the tests allowing us to establish the veracity of the mathematical relations, on the one hand, and the evolution of the measured parameter value in the three travel regimes, on the other hand.
\end{abstract}

Keywords: transport, monitoring, control, safety.

\section{Introduction}

The main working parameters of the means of road transport are the maximum weight transported (mass of the product transported + mass of the means of transport), the travel speed and the braking parameters.

Depending on these parameters, the proper rolling system, the constructive and functional characteristics are established, with direct implications for the rolling track compression and wear, tyre tread wear, rolling resistance and implicitly of the cost of the transport operation itself [1-3].

During running of the system made up of a tractor vehicle (hereinafter referred to as auto-tractor) and a trailer, additional load (weight) transfers from the trailer to the tractor appear. These transfers occur both during normal running, on a horizontal road, when at the constant weight transferred as a result of the construction of the means of transport (for example, a semi-trailer) an additional weight is added caused by the inertia force of the means of transport appearing at deceleration in case of normal rolling, downward rolling or during system braking [4-6].

On the contrary, in the acceleration or upward rolling phases there is a load discharge of the tractor.

At present, for the existing transport systems these additional weight transfers to the auto-tractor $[1 ; 2 ; 4 ; 5 ; 7 ; 8]$ cannot be quantified, except theoretically, as too much, uncontrolled load intake can affect the quality of the transport [9] or in extreme cases can lead to occurrence of malfunctions that can cause accidents.

Existing rolling systems perform as the main functions of load supporting, rolling, braking and partial shock absorption.

The rolling system studied in this paper is equipped with a load monitoring installation that allows, besides the functions that any existing system performs, to continuously measure the weight of the means of transport by providing real-time information on the weight variation transferred to the tractor in the aforementioned transport situations, as well as on the air pressure in the tires according to the transported load. 
The information provided by the load monitoring installation can be used both in the design and realization stage of the means of transport and in the choice of the auto-tractor in the aggregate as well as in the correct choice of the air pressure in the tires or in the monitoring of the means of transport loading.

\section{Material and method}

We consider anarticulated vehicle made up of an auto-tractor and a means of transport, in this case, an agricultural tractor and an agricultural semi-trailer moving on a sloping land that is in the accelerating phase.

The action of the semi-trailer on the tractor (Fig. 1) is represented by the connecting forces $R$ and $F_{t}$. Force $R$ represents the part of the semi-trailer total weight $G_{s}$ that is distributed to the tractor and which contributes to increasing the tractor adhesion weight, while the force $F_{t}$ is the traction force necessary to tow the semi-trailer $[1 ; 2 ; 4 ; 10]$.

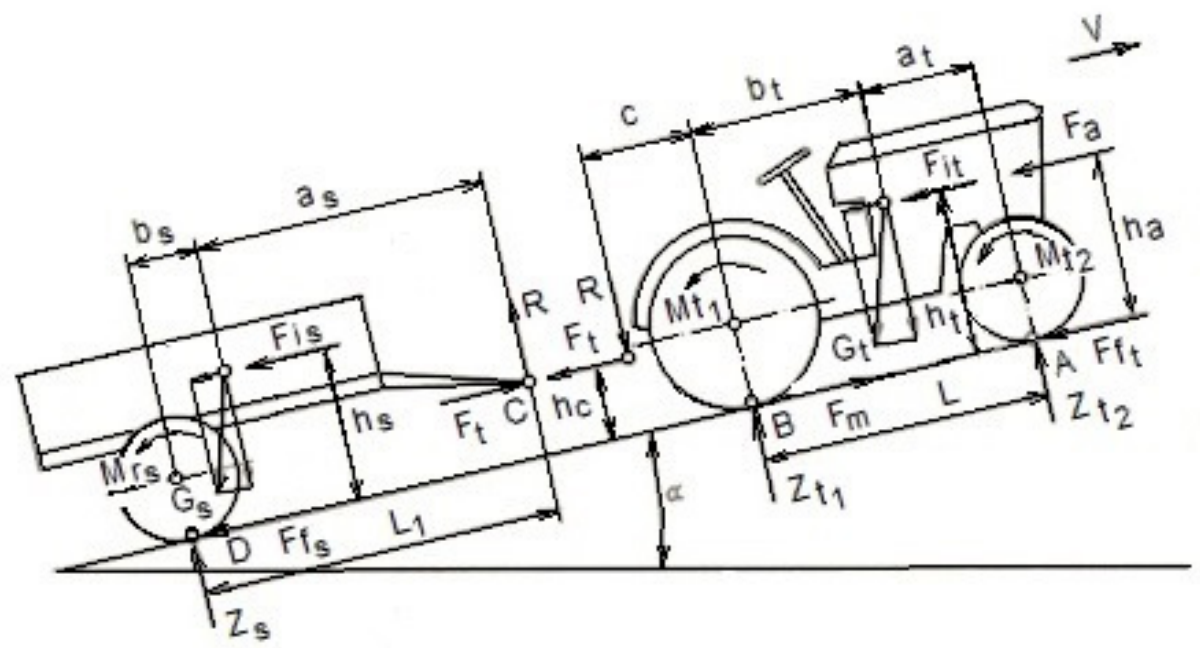

Fig. 1. Forces and moments acting on tractor-semi-trailer system

The resistance force of the semi-trailer is determined by the relation (1):

$$
F_{i s}=f \cdot Z_{s}=f\left(G_{s} \cdot \cos \alpha-R\right),
$$

where $f$-rolling resistance coefficient;

$G_{s}$ - total weight of the semi-trailer, daN;

$R$ - part of the semi-trailer total weight to be distributed to the tractor, daN.

The inertia force of the semi-trailer is determined by the relation (2):

$$
F_{i s}=\frac{G_{s}}{g} \cdot \delta_{s} \cdot \frac{d v}{d t},
$$

where $g$-gravitational acceleration, $\mathrm{m} / \mathrm{s}^{2}$;

$\delta_{s}$ - semi-trailer masses coefficient in rotation motion (transport wheels);

$d v / d t$ - variation of articulated vehicle acceleration/deceleration, $\mathrm{m} \cdot \mathrm{s}^{-2}$.

The moment of semi-trailer rolling resistance is determined by the relation (3):

$$
M_{r s}=f \cdot r_{s} \cdot Z_{s}=f \cdot r \cdot\left(G_{s} \cdot \cos \alpha-R\right),
$$

where $r_{s}-$ dynamic radius of the semi-trailer wheels, $\mathrm{m}$;

$Z_{s}$ - normal reaction of the ground on the semi-trailer wheels, daN.

The traction force necessary to tow the semi-trailer is determined by the relation (4):

$$
F_{t}=F_{f s}+F_{i s}+G_{s} \sin \alpha=f \cdot Z_{s}+\frac{G_{s}}{g} \cdot \delta_{s} \cdot \frac{d v}{d t}+G_{s} \sin \alpha .
$$


The normal reaction of the ground on the semi-trailer wheels is determined from the moment equation written in the coupling point $\mathrm{C}$, according to the relation (5):

$$
Z_{s} \cdot L_{1}+F_{f s} \cdot h_{c}-M_{r s}-F_{i s}\left(h_{s}-h_{c}\right)-G_{s} \cdot a_{s} \cdot \cos \alpha-G_{s} \sin \alpha\left(h_{s}-h_{c}\right)=0 .
$$

Replacing $F_{f s}$ and $M_{r s}$ in relation (5) with their expressions given by relations (2) and (3) and making the grouping of common factors, the expression of the $Z_{s}$ reaction according to the relation (6) is determined:

$$
Z_{s}=\frac{\left(F_{i s}+G_{s} \cdot \sin \alpha\right) \cdot\left(h_{s}-h_{c}\right)+G_{s} \cdot a_{s} \cdot \cos \alpha}{L_{1}+f\left(h_{c}-r_{s}\right)} .
$$

Component $\mathrm{R}$ is determined by the relation (7):

$$
R=G_{s} \cdot \cos \alpha-Z_{s}
$$

Or replacing component $\mathrm{R}$ with the expression in relation (6) results in the following:

$$
R=\frac{G_{s} \cdot \cos \alpha\left[b_{s}+f\left(h_{c}-r_{s}\right)\right]-\left(F_{i s}+G_{s} \cdot \sin \alpha\right) \cdot\left(h_{s}-h_{c}\right)}{L_{1}+f\left(h_{c}-r_{s}\right)} .
$$

Replacing $Z_{s}$ reaction in relation (4) with its expression in relation (6), grouping the terms, results in the expression for $F_{t}$, according to relation (8):

$$
F_{t}=\frac{f \cdot G_{s} \cdot a_{s} \cdot \cos \alpha+\left(F_{i s}+G_{s} \cdot \sin \alpha\right)\left[L_{1}+f\left(h_{s}-r_{s}\right)\right]}{L_{1}+f\left(h_{c}-r_{s}\right)} .
$$

The ground normal reactions on the wheels of the tractor with the semi-trailer are determined from the moment equations written in the support points $A$ and $B$, the final expressions being according to the relations $(9,10)$ :

$$
\begin{aligned}
& Z_{t 1}=\frac{G_{t} \cdot b_{t} \cdot \cos \alpha-\left(G_{t} \cdot \sin \alpha+F_{i t}+F_{a}\right) h_{t}-R \cdot c-F_{t} \cdot h_{c}-M_{r t}}{L}, \\
& Z_{t 2}=\frac{G_{t} \cdot a_{t} \cdot \cos \alpha+\left(G_{t} \cdot \sin \alpha+F_{i t}+F_{a}\right) \cdot h_{t}+R(L+c)+F_{t} \cdot h_{c}+M_{r t}}{L},
\end{aligned}
$$

where $M_{r t}=M_{r t 1}+M_{r t 2}=f \cdot r_{t}\left(G_{t} \cdot \cos \alpha+R\right)-$ rolling resistance moment of the tractor (including the part of the semi-trailer weight $\mathrm{R}$ to be distributed to the tractor). $r_{t}$-dynamic radius of the tractor wheel, $\mathrm{m}$.

\section{Results and discussion}

The tests were carried out with articulated vehicle made up of an autotractor and a means of transport, in this case a New Holland TD80D agricultural tractor and a one-axle agricultural semitrailer, Fig. 2, which moves on a horizontal ground, the semi-trailer being equipped with a load monitoring installation.

In this paper we are interested in the sizes that act on the semi-trailer, namely: $Z_{s}, R$.

To verify correct functionality of the load monitoring installation, we determined it by weighing, when stationary, using the classic weighing system: $G_{s}=7250 \mathrm{~kg} ; Z_{s}=6268 \mathrm{~kg} ; R=982 \mathrm{~kg}$.

In a first stage of the tests using the load monitoring installation we determined, when stationary, the mass of the loaded semi-trailer, $G_{s}=7125 \mathrm{~kg}$ and its distribution on the axis. The values measured during the experiments are: $Z_{s}=6168 \mathrm{~kg}$ and the component to be transferred to the tractor, $R=957 \mathrm{~kg}$.

It is to be noted that the differences are insignificant, so the installation is functioning correctly, the deviations being of 1.60-2.6\%, a value falling within the equipment construction error margin. 


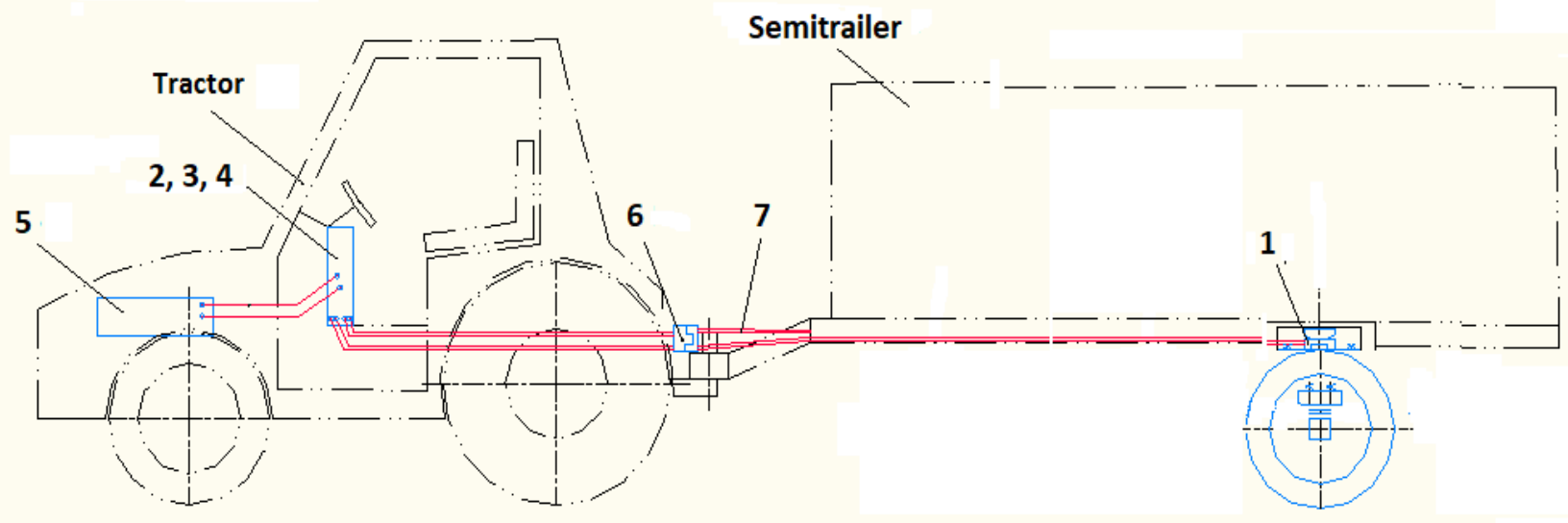

Fig. 2. Load monitoring installation: 1 - force transducer; 2 - force amplifier; 3 - micro PLC; 4 - operating terminal; 5 - accumulator battery; 6 - bipolar fuse; 7 - connecting cables

We also measured and calculated the constructive dimensions of the semi-trailer, the positions of its centre of gravity and the coefficient of the masses in rotation motion (for semi-trailer wheels), as follows:

$$
L_{1}=4.8 m ; a_{s}=4.15 m ; b_{s}=0.65 m ; h_{s}=1.6 m ; h_{c}=0.45 m ; r_{s}=0.55 m ; \delta_{s}=1.055
$$

For $\frac{d v}{d t}$ was taken as the average value of $0.3 \mathrm{~m} \cdot \mathrm{s}^{-2}$, from [1].

The values for $Z_{s a}$ and $R_{a}$ in the case of articulated vehicle acceleration (marked with "a"), on horizontal terrain, are calculated with the relations $(6 ; 7)$ using the determined and measured values as follows:

$$
\begin{gathered}
Z_{s a}=\frac{\frac{7250}{9.81} \cdot 1.055 \cdot 0.3(1.6-0.45)+7250 \cdot 5.15}{4.8+0.01(0.45-0.55)}=6326 \mathrm{daN} \\
R_{a}=\frac{7250 \cdot[0.65+0.01(0.45-0.55)]-\frac{7250}{9.81} \cdot 0.3 \cdot 1.055(1.6-0.45)}{4.8+0.01(0.45-0.55)}=924 \mathrm{daN}
\end{gathered}
$$

Similarly, the values for $Z_{s d}$ and $R_{d}$ are calculated according to the relations $(6 ; 7)$ in the case of articulated vehicle deceleration (marked with " $d$ "); only that in this case the inertia force of the semitrailer has the opposite direction of action. Using the measured and calculated values presented above we have:

$$
Z_{s d}=6213 d a N ; R_{d}=1037 d a N
$$

The values for $Z_{s f}$ and $R_{f}$ in the case of the articulated vehicle sudden braking (marked with ' $f$ ') are calculated with the relations $(6 ; 7)$, where the inertia force of the semi-trailer has the opposite direction of action and the deceleration value is $1.45 \mathrm{~m} \cdot \mathrm{s}^{-2}$, which means the subtraction between deceleration of the tractor itself, $6.05 \mathrm{~m} / \mathrm{s}^{2}$ and articulated vehicle $4.45 \mathrm{~m} \cdot \mathrm{s}^{-2}$, as follows:

$$
Z_{s f}=5999 \mathrm{daN} ; R_{f}=1251 \mathrm{daN}
$$

For moving on slope the calculations are similar only that the slope angle of inclination is introduced in the relations.

Driving tests were performed for two situations commonly encountered during transport, for each situation there were 5 determinations made, namely: 
Driving at a constant speed of $30 \mathrm{~km} \cdot \mathrm{h}^{-1}$, deceleration for a period of 5 seconds, when the operator raises the foot from the tractor accelerator pedal followed by acceleration to $30 \mathrm{~km} \cdot \mathrm{h}^{-1}$, the results determined for $Z_{s}$ and $R$ during deceleration/acceleration periods being shown in Table 1;

Table 1

Determination of $Z_{s}$ and $\boldsymbol{R}$ values in the case of articulated vehicle deceleration/acceleration

\begin{tabular}{|c|c|c|c|c|c|c|c|c|c|c|}
\hline \multirow[t]{2}{*}{$\begin{array}{l}\text { Determined } \\
\text { parameter }\end{array}$} & \multicolumn{6}{|c|}{$\begin{array}{c}\qquad \frac{d v}{d t}=0.3 \mathrm{~m} \cdot \mathrm{s}^{-2} \\
\text { Decelerationduringdriving/ Test no. }\end{array}$} & \multicolumn{4}{|c|}{$\frac{d v}{d t}, \mathrm{~m} \cdot \mathrm{s}^{-2}$} \\
\hline & 1 & 2 & 3 & 4 & 5 & Average & 0.1 & 0.3 & 0.5 & 0.7 \\
\hline$Z_{s d}, \mathrm{daN}$ & 6235 & 6220 & 6210 & 6226 & 6210 & 6220 & 6250 & 6220 & 6176 & 6139 \\
\hline$R_{d}, \mathrm{daN}$ & 1015 & 1030 & 1040 & 1025 & 1040 & 1030 & 1000 & 1030 & 1074 & 1111 \\
\hline & \multicolumn{6}{|c|}{ Accelerationduringdriving / Test no. } & & & & \\
\hline$Z_{s a}, \mathrm{daN}$ & 6315 & 6318 & 6332 & 6320 & 6325 & 6322 & 6288 & 6322 & 6363 & 6400 \\
\hline$R_{a}, \mathrm{daN}$ & 935 & 932 & 918 & 930 & 925 & 928 & 962 & 928 & 887 & 850 \\
\hline
\end{tabular}

Driving at a constant speed of $30 \mathrm{~km} \cdot \mathrm{h}^{-1}$ followed by sudden braking to stopping the articulated vehicle, the results determined for $Z_{s}$ and $R$ during the braking period being shown in Table 2.

In all the above-mentioned situations, the determined sizes are the soil reaction on the semi-trailer wheels, $Z_{s}$ and the additional load of the rear axle of the tractor $R$, these sizes being in fact those, the value of which varies significantly during transport.

Since during the testing period the registered values were very numerous, the highest values of each test were mentioned in Tables 1 and 2. Their variation is graphically shown in Fig. 34 .

Table 2

\section{Determination of $Z_{s}$ and $R$ values in the case of articulated vehicle braking}

\begin{tabular}{|c|c|c|c|c|c|c|c|c|c|c|}
\hline \multirow{2}{*}{$\begin{array}{c}\text { Determined } \\
\text { parameter }\end{array}$} & \multicolumn{9}{|c|}{$d v$} & \multicolumn{5}{c|}{$\frac{d v}{d t}, \mathrm{~m} \cdot \mathrm{s}^{-2}$} \\
& $\mathbf{1}$ & $\mathbf{2}$ & $\mathbf{3}$ & $\mathbf{4}$ & $\mathbf{5}$ & Average & $\mathbf{1 . 2 5}$ & $\mathbf{1 . 4 5}$ & $\mathbf{1 . 6 5}$ & $\mathbf{2 . 0 0}$ \\
\cline { 2 - 11 } & $\mathbf{1} \cdot \mathrm{s}^{-2}$ & $\mathbf{6 0 0 8}$ & 6035 & 6008 & 5961 & 5896 \\
\hline$Z_{s f}$, daN & 5985 & 6005 & 6020 & 6010 & 6020 & $\mathbf{6 0 0 8}$ & 1215 & 1242 & 1289 & 1354 \\
\hline$R_{f}$, daN & 1265 & 1245 & 1230 & 1240 & 1230 & $\mathbf{1 2 4 2}$ & 1215 & \\
\hline
\end{tabular}
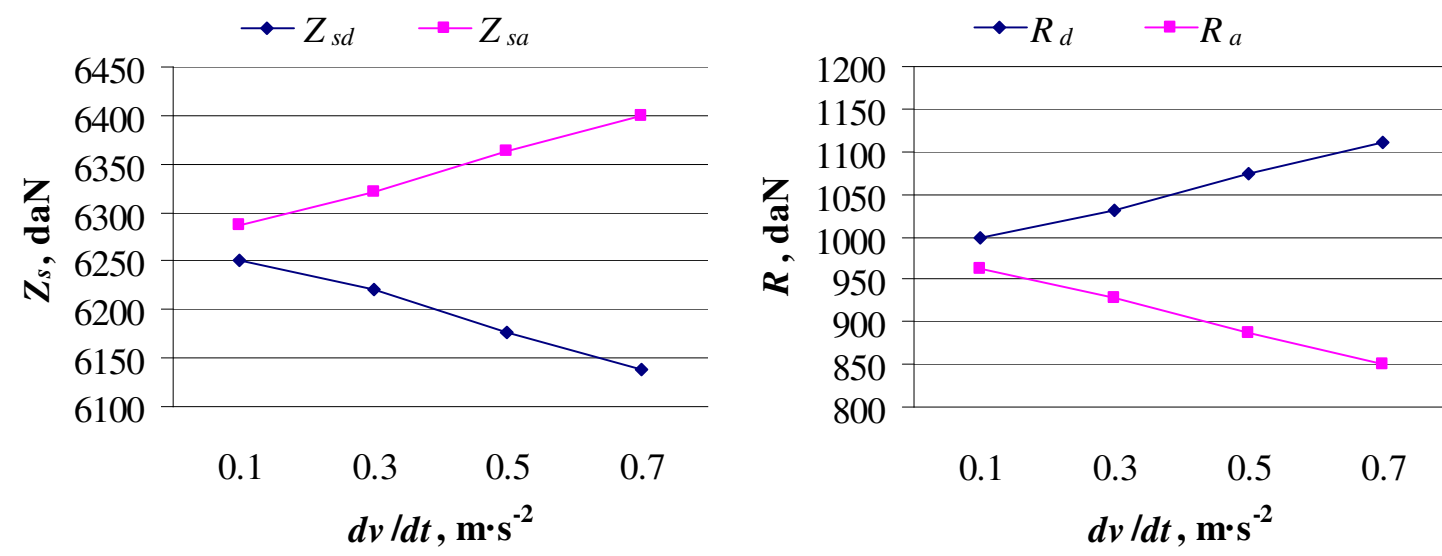

Fig. 3.Variation of $\mathbf{Z}_{\mathrm{s}}$ and $\mathbf{R}$ on deceleration/ acceleration 

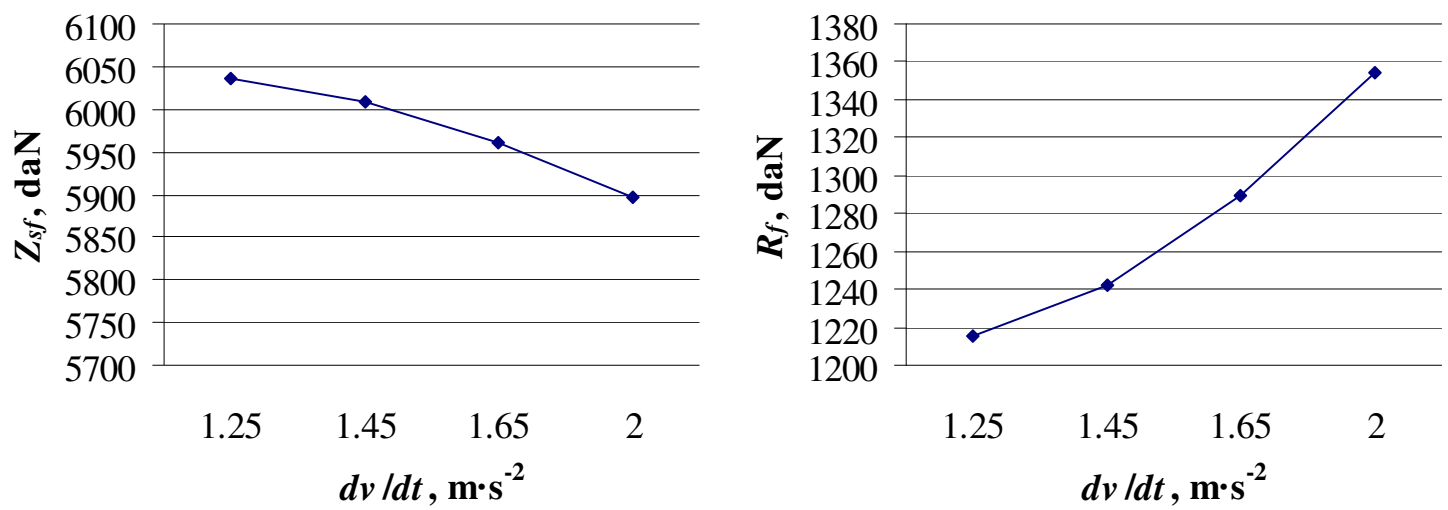

Fig. 4.Variation of $Z_{s}$ and $R$ on braking

\section{Conclusions}

1. During running of a system consisting of a tractor vehicle and a trailer, there are additional load transfers (weight) from the trailer to the tractor, which, at present, can be quantified only theoretically for the existing transport systems;

2. The rolling system covered by this paper is equipped with a load monitoring installation that carries out continuous real-time measurement of the load sustained by the trailer rolling system and its variation as a result of the load transfer to the tractor while driving;

3. The values measured during experimentation for the load sustained by the trailer rolling system, when stationary close to those determined by the classic weighing system, the deviations being $1.75 \%$, a value falling within the equipment construction error margin;

4. The values measured during experimentation, while the articulated vehicle was running, for the reaction of the ground on the trailer rolling system, $Z_{s}$ and for load transfer from the semi-trailer to the tractor, $R$ are very close to those determined theoretically with mathematical relations, the deviations calculated as the ratio of the theoretically calculated value and mean value measured in the experiments being: for $Z_{s a}, 0.1 \%$ when accelerated; for $Z_{s d},-0.099 \%$ when decelerated; for $Z_{s f},-0.0998 \%$ when braked; for $R a,-0.0995 \%$ when accelerated; for $R_{d}, 0.0679 \%$ when decelerated; for $R_{f}, 0.0724 \%$ when braked.

5. The permanent knowledge of the weight distributed to the trailer axle helps us, among others, set up the air pressure in the tires according to their type, the size of the load transported, the condition and the nature of the rolling track in order to achieve an optimal transport operation.

\section{Acknowledgements}

The work was performed under the project "Increasing the competitiveness of SC ELECTROPUTERE VFU PASCANI SA through assimilation into production of an Intelligent rolling system, designed to general and technological land transport equipment", Contract 5/PTE/2016 funded by the Executive Agency for Higher Education, Research, Development and Innovation Funding UEFISCDI within the PN-III-CERC-CO-PTE-2016 Program.

\section{References}

[1] Tecusan N., Ionescu A., Tractoaresi Automobile (Tractors and Automobiles), EdituraDidacticasiPedagogicaBucuresti (Technical Publishing House Bucharest), 1982, pp. 65-88.

[2] Untaru M, Stoicescu A, Dinamicaautovehiculelorpe roti (Dymanics of Wheels Automotive), EdituraDidacticasiPedagogicaBucuresti (Technical Publishing House Bucharest), 1981, pp. 126-146.

[3] Kumar A. A., Tewari V.K., Gupta C., Kumar N., Visual Basic Program and Instrumentation System for Power and Energy Mapping of Tractor Implement, Engineering in Agriculture, Environment and Food, vol.10, Issue 2, 2017, pp. 121-132.

[4] Badescu M.,Iordache S., Ivancu B., Persu C.,Bunduchi G.,Epure M.,VladutV.,Theoretical Study of the System of Forces and Moments Acting on Tractor-Semitrailer Aggregate, into Rectilinear 
Motion, ANNALS of Faculty Engineering Hunedoara - International journal of Engineering, Tome XII, August 2014.

[5] Bădescu M., Iordache S., Manea D., Sorică C., Brăcăcescu C., Boruz S.,Epure M., VlăduţV., Analysis of Forces and Reaction Moments Acting on Tractor Semitrailer Agregate on Sloped Roads, ANNALS of Faculty Engineering Hunedoara - International journal of Engineering, Tome XII, November 2014, pp. 29-36.

[6] Ciupercă R., Popa L., Nedelcu A.,Borisov B., AtanasovAt.-Braking of trailer endowedwithinertialbrakingsystem, working in aggregatewith tractor, INMATEH - Agricultural Engineering, Vol. 32, No. 3 / 2010, pp. 51-58.

[7] Iordache S., Boruz S.,Vlăduţ V.,Sorică C., Manea D., Brăcăcescu C., EpureM.,The Study of Braking Dynamics on Tractors with Wheels and Influence of the Forces Which Appear at Movement on Braking Capability, ANNALS of Faculty Engineering Hunedoara - International journal of Engineering, Tome XII, November 2014, pp. 73-78.

[8] Iordache S., Bădescu M., Boruz S.,Usenko M., Cujbescu D., Vlăduţ V., Study of Tractor ShaftBrakingForces Distribution Influence on WheeledTractorsBraking, ANNALS of Faculty Engineering Hunedoara - International journal of Engineering, Tome XII, August 2014, pp. 325-330.

[9] Żebrowski J., Traction efficiency of a wheeled tractor in construction operations, AutomationinConstruction, vol.19, Issue 2, 2010, pp. 100-108.

[10] Ciuperca R., Popa L., Nedelcu A., Dymanics of tractor-semitrailer braking system, $47^{\mathrm{TH}}$ International Conference of Departments of Design of Machine Elements and Mechanisms,2006, Prague, pp. 43-47. 